\title{
Some Topological Indices of Subgroup Graph of Symmetric Group
}

\author{
Abdussakir \\ Department of Mathematics Education, Univesitas Islam Negeri Maulana Malik Ibrahim Malang, Indonesia \\ Received July 8, 2019; Revised August 10, 2019; Accepted August 22, 2019
}

Copyright $@ 2019$ by authors, all rights reserved. Authors agree that this article remains permanently open access under the terms of the Creative Commons Attribution License 4.0 International License

\begin{abstract}
The concept of the topological index of a graph is increasingly diverse because researchers continue to introduce new concepts of topological indices. Researches on the topological indices of a graph which initially only examines graphs related to chemical structures begin to examine graphs in general. On the other hand, the concept of graphs obtained from an algebraic structure is also increasingly being introduced. Thus, studying the topological indices of a graph obtained from an algebraic structure such as a group is very interesting to do. One concept of graph obtained from a group is subgroup graph introduced by Anderson et al in 2012 and there is no research on the topology index of the subgroup graph of the symmetric group until now. This article examines several topological indices of the subgroup graphs of the symmetric group for trivial normal subgroups. This article focuses on determining the formulae of various Zagreb indices such as first and second Zagreb indices and co-indices, reduced second Zagreb index and first and second multiplicatively Zagreb indices and several eccentricity-based topological indices such as first and second Zagreb eccentricity indices, eccentric connectivity, connective eccentricity, eccentric distance sum and adjacent eccentric distance sum indices of these graphs.
\end{abstract}

Keywords Topological Indices, Zagreb Index, Subgroup Graph, Trivial Normal Subgroup, Symmetric Group

\section{Introduction}

The topological index of a finite graph is a number associated with the graph and this number is invariant under automorphism [1]. Topological index sometimes called a graph-theoretical descriptor [2-4] or molecular structure descriptor [5] of a graph. Various topological indices have been used to solve problem in biology and chemistry. Three major classifications of the topological index of a graph are based on degree, distance and the eccentricity of vertex in the graph.

The degree-based topological indices for examples Randic index and its variations [6-8], Zagreb index and its variations [6, 9-16], forgotten topological index and its variations [17-21], Narumi-Katayama index [6], atom-bond-connectivity index and its variations [6,7], Harmonic index [22-25], geometric-arithmetic index its variations [26, 27], and sum-connectivity index and its variations [28-31]. The distance-based topological indices for instances Wiener index and its variations [32,33] and Harary index and its variations [34-38]. While the eccentricity-based topological indices for example total eccentricity index [39, 40] and first and second Zagreb eccentricity indices [41]. Based on these three major topological indices, new topological indices are developed for examples Schultz index [42], Gutman index [43-45], additively and multiplicatively Weighted Harary indices [46-49], eccentric connectivity index [50-53], connective eccentricity index [54], eccentric distance sum [3,55-59] and adjacent eccentric distance sum index [5].

Research on the topological index was initially related to graphs of biological activity or chemical structures and reactivity and researches in this regard continue, for example see [59-63]. On the other hand, several studies began to examine the topological index of graphs that are not of chemical structure and reactivity or biological activity, for example [54,64-72]. When several researchers introduced new concepts about graphs obtained from an algebraic structure, research on topological indices on these graphs began to emerge, for example [73].

One concept of graphs obtained from a group is the concept of subgroup graph that was introduced by Anderson, Fasteen and LaGrange [74]. Referring to the definition of the subgroup graph by Anderson et al. [74], let $G$ is a group and $H$ is a normal subgroup in $G$. The subgroup graph $\Gamma_{H}(G)$ of group $G$ is a simple and undirected graph with all elements of $G$ as its vertices and $u v \in E\left(\Gamma_{H}(G)\right)$ whenever $u v \in H$ for $u, v \in G$ and $u$ $\neq v$. As a result, the complement $\overline{\Gamma_{H}(G)}$ of the subgroup graph $\Gamma_{H}(G)$ is also simple and undirected [75]. Several 
studies related to graphs from a group have been widely reported, mostly of dihedral group [73,76-82] and are still rare from symmetric groups [82-84]. Therefore, this article will examine the formulae of various Zagreb indices and eccentricity-based topological indices of the subgroup graph of the symmetric group.

\section{Materials and Methods}

All graphs in the present article is finite, simple, undirected and connected. For graph $G=(V(G), E(G))$, the order of $G$ is $p(G)=|V(G)|$ and its size is $q(G)=$ $|E(G)|$. Let $\operatorname{deg}(u)$ denoted the degree of a vertex $u$ in $G$. If $\operatorname{deg}(u)=0$, then $u$ is an isolated vertex. If $\operatorname{deg}(u)=1$, then $u$ is an end-vertex. Let $d(u, v)$ denoted the distance of vertex $u$ and vertex $v$ in $G$. The eccentricity $e(u)$ of a vertex $u$ is $e(u)=\sup \{d(u, v): v \in V(G)\}$. The total distance $D(u)$ of a vertex $u$ in $G$ is $D(u)=\sum_{v \in V(G)} d(u, v)$.

The complement $\bar{G}$ of graph $G$ is a graph with $V(\bar{G})=$ $V(G)$ and $u v \in E(\bar{G})$ whenever $u v \notin E(G)$ [85]. Graph $\bar{G}$ is connected if $G$ is disconnected. For $U \subset$ $E(G)$, graph $G-U$ is obtained by erasing all elements of $U$ from $G$.

For graphs $G$ and $H$, the union graph $G \cup H$ has $V(G \cup$ $H)=V(G) \cup V(H) \quad$ and $\quad E(G \cup H)=E(G) \cup$ $E(H)$. Graph $G$ is written as $G=m H$ if $G$ consists of $m$ copies of graph $H$, In this paper, $K_{p}$ denotes the complete graph of order $p$. Then, $\overline{K_{p}}=p K_{1}$.

Zagreb index is the second oldest of degree-based topological index and Randic index is the first oldest. Firstly, the definition of various Zagreb index of graph $G$ that will be used in this article are presented. After that, the definitions of several eccentricity-based topological indices which will also be used in this article are presented.

The following definitions refer to a graph $G=(V(G)$, $E(G))$.

The first and second Zagreb indices of $G$ are [17]

$$
M_{1}(G)=\sum_{u \in V(G)}(\operatorname{deg}(u))^{2}
$$

and

$$
M_{2}(G)=\sum_{u v \in E(G)} \operatorname{deg}(u) \operatorname{deg}(v)
$$

The first and second Zagreb co-indices of $G$ are [11]

$$
\overline{M_{1}}(G)=\sum_{u v \notin E(G)}[\operatorname{deg}(u)+\operatorname{deg}(v)]
$$

and

$$
\overline{M_{2}}(G)=\sum_{u v \notin E(G)} \operatorname{deg}(u) \operatorname{deg}(v)
$$

The reduced second Zagreb index of $G$ is [12,14]

$$
R M_{2}(G)=\sum_{u v \in E(G)}[\operatorname{deg}(u)-1][\operatorname{deg}(v)-1]
$$

The first and second multiplicative Zagreb indices of $G$ are $[13,15]$

$$
\Pi_{1}(G)=\prod_{u \in V(G)}(\operatorname{deg}(u))^{2}
$$

and

$$
\Pi_{2}(G)=\prod_{u v \in E(G)} \operatorname{deg}(u) \operatorname{deg}(v)
$$

The first and second Zagreb eccentricity indices of $G$ are [16]

$$
E_{1}(G)=\sum_{u \in V(G)}(e(u))^{2}
$$

and

$$
E_{2}(G)=\sum_{u v \in E(G)} \mathrm{e}(u) \mathrm{e}(v)
$$

The eccentric connectivity index of $G$ is [86]

$$
\xi^{c}(G)=\sum_{v \in V(G)} e(v) \operatorname{deg}(v)
$$

The connective eccentricity index of $G$ is [63]

$$
C^{\xi}(G)=\sum_{v \in V(G)} \frac{\operatorname{deg}(v)}{e(v)}
$$

The eccentric distance sum index of $G$ is [59]

$$
\xi^{d}(G)=\sum_{v \in V(G)} e(v) D(v)
$$

The adjacent eccentric distance sum index of $G$ is [5]

$$
\xi^{S v}(G)=\sum_{v \in V(G)} \frac{e(v) D(v)}{\operatorname{deg}(v)}
$$

\section{Main Result}

For a positive integer $n \geq 3$, the symmetric group $S_{n}$ contains all permutations on the set $\mathbb{N}_{n}=$ $\{1,2,3, \ldots, n\}$ under the composition function operation. The symmetric group $S_{n}$ is a non-commutative group of order $n$ !. For distinct elements $x_{1}, x_{2}, \ldots, x_{k}(k \leq n)$ in $\mathbb{N}_{n}$, a cycle $\left(x_{1} x_{2} \cdots x_{k}\right)$ states a permutation $\pi$ in $S_{n}$ such that $\pi\left(x_{i}\right)=x_{i+1}$ and $\pi\left(x_{k}\right)=x_{1}$ and $\pi$ maps any other element of $\mathbb{N}_{n}$ to itself. The cycle $\left(x_{1} x_{2} \cdots x_{k}\right)$ is called $k$-cycle or cycle with the length $k$. The 2-cycle is called transposition. The order of a $k$-cycle is $k$. The order of a product of disjoint transpositions has order 2 . The order of permutation $\rho$ in $S_{n}$ is 1 if and only if $\rho=(1)$, where (1) is identity element of $S_{n}$.

Throughout this paper, let $X$ is the set of permutations in $S_{n}$ with order less than 3 and let $Y$ is the set of permutations in $S_{n}$ with order more than 2. Hence, $S_{n}=$ $X \cup Y$.

\section{Theorem 3.1.}

$$
|X|=\left\{\begin{array}{l}
1+\sum_{m=1}^{\frac{n-1}{2}} \frac{n !}{2^{m} m !(n-2 m) !}, \text { if } n \text { is odd } \\
1+\sum_{m=1}^{\frac{n}{2}} \frac{n !}{2^{m} m !(n-2 m) !}, \text { if } n \text { is even }
\end{array}\right.
$$

Proof. The set $X$ consists of identity permutation and permutations in term of products of disjoint 2-cycles. The number of permutations in $S_{n}$ with a given cycle structure is

$$
\frac{n !}{\prod_{k=1}^{n}\left(m_{k}\right) ! k^{m_{k}}}
$$


where $m_{k}$ denotes the number of $k$-cycles. By (14), the number permutation in the term of products of disjoint 2-cycles is

$$
\sum_{m=1}^{\frac{n-1}{2}} \frac{n !}{2^{m} m !(n-2 m) !} \text {, if } n \text { is odd }
$$

or

$$
\sum_{m=1}^{\frac{n}{2}} \frac{n !}{2^{m} m !(n-2 m) !} \text {, if } n \text { is even. }
$$

This proves the theorem.

\section{Theorem 3.2.}

$|Y|$ is even and $|Y|=n !-|X|$.

Proof. Let $\delta$ is any element in $Y$. Then $\delta$ is a permutation of order more than 2. It implies that $\delta^{-1}$ is also a permutation of order more than 2. Hence, $Y$ consists of permutations together with their inverses. This proves that $|Y|$ is even. By Theorem 3.1, $|Y|=\left|S_{n}\right|-|X|=n$ ! $|X|$.

\section{Corollary 3.3.}

$|X|$ is even

Proof. Because for $n \geq 3,\left|S_{n}\right|=n$ ! is even and, by Theorem 3.2, $|Y|$ is even, obviously $|X|$ is even.

The subgroup graph of a group will be simple and undirected if the subgroup is a normal subgroup. For symmetric group $S_{n}$, the trivial normal subgroup is $\{(1)\}$ and $S_{n}$. This article only considers these two trivial normal subgroups of $S_{n}$.

\section{Theorem 3.4.}

$\Gamma_{S_{n}}\left(S_{n}\right)$ is complete with order $n$ !

Proof. The proof is obvious.

Along this paper, let the set of all permutations of order less than 3 is $X=\left\{w_{1}, w_{2}, \ldots, w_{|X|}\right\}$ where $w_{1}=(1)$ and let the set of all permutations of order more than 2 in $S_{n}$ is $Y=$ $\left\{u_{1}, u_{2}, \ldots, u_{|Y| / 2}, v_{1}, v_{2}, \ldots, v_{|Y| / 2}\right\}$ where $v_{i}=\left(u_{i}\right)^{-1}$.

\section{Theorem 3.5.}

$\Gamma_{\{(1)\}}\left(S_{n}\right)$ is disconnected with size

$$
q\left(\Gamma_{\{(1)\}}\left(S_{n}\right)\right)=\frac{|Y|}{2} .
$$

Proof. By definition of the subgroup graph, the edge set of $\Gamma_{\{(1)\}}\left(S_{n}\right)$ is

$$
E\left(\Gamma_{\{(1)\}}\left(S_{n}\right)\right)=\left\{u_{i} v_{i}: 1 \leq i \leq \frac{|Y|}{2}\right\} .
$$

Hence, in $\Gamma_{\{(1)\}}\left(S_{n}\right)$, all permutations in $Y$ are end-vertices and all permutations in $X$ are isolated vertices. Thus, $\Gamma_{\{(1)\}}\left(S_{n}\right)$ is disconnected with $q\left(\Gamma_{\{(1)\}}\left(S_{n}\right)\right)=$ $|Y| / 2$.

\section{Corollary 3.6.}

The number of isolated-vertices in $\Gamma_{\{(1)\}}\left(S_{n}\right)$ is

$$
|X|=\left\{\begin{array}{l}
1+\Sigma_{m=1}^{\frac{n-1}{2}} \frac{n !}{2^{m} m !(n-2 m) !}, \text { if } n \text { is odd } \\
1+\Sigma_{m=1}^{\frac{n}{2}} \frac{n !}{2^{m} m !(n-2 m) !}, \text { if } n \text { is even }
\end{array}\right.
$$

and the number of end-vertices in $\Gamma_{\{(1)\}}\left(S_{n}\right)$ is

$$
|Y|=n !-|X| \text {. }
$$

Proof. From the proof of Theorem 3.5.

According to Corollary 3.6., then $\Gamma_{\{1\}}\left(S_{n}\right)$ can be written as

$$
\Gamma_{\{1\}}\left(S_{n}\right)=\frac{1}{2}|Y| K_{2} \cup|X| K_{1} .
$$

with size as presented in (16). Therefore, the complement of $\Gamma_{\{1\}}\left(S_{n}\right)$ is

$$
\left.\overline{\Gamma_{\{1\}}\left(S_{n}\right)}=K_{n !}-\left\{u_{i} v_{i}: 1 \leq i \leq \frac{|Y|}{2}\right\}\right) .
$$

Thus, the following two theorems are obtained.

\section{Theorem 3.7.}

$\operatorname{In} \overline{\Gamma_{\{(1)\}}\left(S_{n}\right)}$,

$$
\operatorname{deg}\left(u_{i}\right)=\operatorname{deg}\left(v_{i}\right)=n !-2
$$

and

$$
\operatorname{deg}\left(w_{j}\right)=n !-1 .
$$

Proof. Since $\overline{\Gamma_{\{(1)\}}\left(S_{n}\right)}=K_{n !}-\left\{u_{i} v_{i}: 1 \leq i \leq \frac{|Y|}{2}\right\}$, then $\quad \operatorname{deg}\left(u_{i}\right)=\operatorname{deg}\left(v_{i}\right)=n !-2(1 \leq i \leq|Y|$ / 2) and $\operatorname{deg}\left(w_{j}\right)=n !-1(1 \leq j \leq|X|)$.

\section{Theorem 3.8.}

In $\overline{\Gamma_{\{(1)\}}\left(S_{n}\right)}$,

a. $\quad d\left(u_{i}, v_{i}\right)=2(1 \leq \mathrm{i} \leq|Y| / 2)$.

b. $\quad d\left(u_{i}, u_{s}\right)=d\left(v_{i}, v_{s}\right)=1$, for $s \neq i(1 \leq \mathrm{i}, \mathrm{s} \leq|Y| / 2)$.

c. $\quad d\left(u_{i}, w_{j}\right)=d\left(v_{i}, w_{j}\right)=1(1 \leq \mathrm{i} \leq|Y| / 2$ and $(1 \leq \mathrm{j}$ $\leq|X|)$

d. $\quad d\left(w_{i}, w_{j}\right)=1$, for $i \neq j(1 \leq \mathrm{i}, \mathrm{j} \leq|X|)$

As the direct consequences of Theorem 3.8., the following two corollaries are obtained.

\section{Corollary 3.9.}

In $\overline{\Gamma_{\{(1)\}}\left(S_{n}\right)}, e\left(u_{i}\right)=e\left(v_{i}\right)=2$ and $e\left(w_{j}\right)=1$.

\section{Corollary 3.10.}

In $\overline{\Gamma_{\{(1)\}}\left(S_{n}\right)}$,

a. $\quad D\left(u_{i}\right)=D\left(v_{i}\right)=n$ !

b. $\quad D\left(w_{j}\right)=n !-1$.

Proof. By Theorem 3.8.

a. $\quad D\left(u_{i}\right)=\sum_{\substack{z \in V\left(\Gamma_{\{(1)\}}\left(S_{n}\right)\right) \\ z \neq v_{i}}} d\left(u_{i}, z\right)+d\left(u_{i}, v_{i}\right)$

$$
=(n !-2) \cdot 1+2=n !
$$


In similar manner, $D\left(v_{i}\right)=n$ !

b. Since $w_{j}$ is adjacent to all other vertices in $\overline{\Gamma_{\{(1)\}}\left(S_{n}\right)}$, it is obvious that $D\left(w_{j}\right)=n !-1$.

Topological indices of $\Gamma_{S_{n}}\left(S_{n}\right)$ and $\overline{\Gamma_{\{(1)\}}\left(S_{n}\right)}$ are presented as the following.

\section{Theorem 3.11.}
a. $\quad M_{1}\left(\Gamma_{S_{n}}\left(S_{n}\right)\right)=n !(n !-1)^{2}$
b. $M_{2}\left(\Gamma_{S_{n}}\left(S_{n}\right)\right)=\frac{n !(n !-1)}{2}(n !-1)^{2}$
c. $\quad R M_{2}\left(\Gamma_{S_{n}}\left(S_{n}\right)\right)=\frac{n !(n !-1)}{2}(n !-2)^{2}$
d. $\Pi_{1}\left(\Gamma_{S_{n}}\left(S_{n}\right)\right)=(n !-2)^{2 \cdot n !}$
e. $\Pi_{2}\left(\Gamma_{S_{n}}\left(S_{n}\right)\right)=(n !-2)^{n !(n !-1)}$
f. $E_{1}\left(\Gamma_{S_{n}}\left(S_{n}\right)\right)=n$ !
g. $E_{2}\left(\Gamma_{S_{n}}\left(S_{n}\right)\right)=\frac{n !(n !-1)}{2}$
h. $\quad \xi^{c}\left(\Gamma_{S_{n}}\left(S_{n}\right)\right)=n !(n !-1)$
i. $\quad C^{\xi}\left(\Gamma_{S_{n}}\left(S_{n}\right)\right)=n !(n !-1)$
j. $\quad \xi^{d}\left(\Gamma_{S_{n}}\left(S_{n}\right)\right)=n !(n !-1)$
k. $\quad \xi^{s v}\left(\Gamma_{S_{n}}\left(S_{n}\right)\right)=n$ !

Proof: By Theorem 3.4. $\Gamma_{S_{n}}\left(S_{n}\right)=K_{n !}$. Therefore, its order and size are $p\left(\Gamma_{S_{n}}\left(S_{n}\right)\right)=n$ ! and $q\left(\Gamma_{S_{n}}\left(S_{n}\right)\right)=$ $n !(n !-1)$. For any $v \in V\left(\Gamma_{S_{n}}\left(S_{n}\right)\right), \operatorname{deg}(v)=n !-$ $1, e(v)=1$ and $D(v)=n !-1$. These lead to the desired proof.

\section{Theorem 3.12.}
a. $\quad M_{1}\left(\overline{\Gamma_{\{(1)\}}\left(S_{n}\right)}\right)=|Y|(n !-2)^{2}+|X|(n !-1)^{2}$
b. $\quad M_{2}\left(\overline{\Gamma_{\{(1)\}}\left(S_{n}\right)}\right)=\frac{3|Y|}{2}\left(\frac{|Y|}{2}-1\right)(n !-2)^{2}+$ $|Y||X|(n !-2)(n !-1)+|X|(|X|-1)(n !-1)^{2}$
c. $\quad \overline{M_{1}}\left(\overline{\Gamma_{\{(1)\}}\left(S_{n}\right)}\right)=|Y|(n !-2)$
d. $\overline{M_{2}}\left(\overline{\Gamma_{\{(1)\}}\left(S_{n}\right)}\right)=\frac{|Y|}{2}(n !-2)^{2}$
e. $\quad R M_{2}\left(\overline{\Gamma_{\{(1)\}}\left(S_{n}\right)}\right)=\frac{|Y|}{2}(n !-3)^{2}$
f. $\quad \Pi_{1}\left(\overline{\Gamma_{\{(1)\}}\left(S_{n}\right)}\right)=(n !-2)^{2|Y|}+(n !-1)^{2|X|}$
g. $\quad \Pi_{2}\left(\overline{\Gamma_{\{(1)\}}\left(S_{n}\right)}\right)=(n !-2)^{3|Y|\left(\frac{|Y|}{2}-1\right)}+[(n !-$
2) $(n !-1)]^{|Y||X|}+(n !-1)^{2|X|(|X|-1)}$
h. $E_{1}\left(\overline{\Gamma_{\{(1)\}}\left(S_{n}\right)}\right)=n !+|Y|$
i. $\quad E_{2}\left(\overline{\Gamma_{\{(1)\}}\left(S_{n}\right)}\right)=3|Y|^{2}+|X|^{2}+2|Y||X|-6|Y|-$ $|X|$

j. $\quad \xi^{c}\left(\overline{\Gamma_{\{(1)\}}\left(S_{n}\right)}\right)=2|Y|(n !-2)+|X|(n !-1)$ k. $\quad C^{\xi}\left(\overline{\Gamma_{\{(1)\}}\left(S_{n}\right)}\right)=|Y| \frac{(n !-2)}{2}+|X|(n !-1)$

l. $\xi^{d}\left(\overline{\Gamma_{\{(1)\}}\left(S_{n}\right)}\right)=2|Y| n !+|X|(n !-1)$

m. $\quad \xi^{s v}\left(\overline{\Gamma_{\{(1)\}}\left(S_{n}\right)}\right)=\frac{2|Y| n !}{n !-2}+|X|$

Proof. By using Theorem 3.7., Corollary 3.9 and Corollary 3.10, then

a. $\quad M_{1}\left(\overline{\Gamma_{\{(1)\}}\left(S_{n}\right)}\right)=\sum_{z \in V\left(\overline{\left.\Gamma_{\{(1)\}}\left(S_{n}\right)\right)}\right.}(\operatorname{deg}(z))^{2}$

$$
\begin{aligned}
& =\sum_{z \in Y}(\operatorname{deg}(z))^{2}+\sum_{z \in X}(\operatorname{deg}(z))^{2} \\
& =|Y|(n !-2)^{2}+|X|(n !-1)^{2}
\end{aligned}
$$

b. $\quad M_{2}\left(\overline{\Gamma_{\{(1)\}}\left(S_{n}\right)}\right)=\sum_{z x \in E\left(\overline{\Gamma_{\{(1)\}}\left(S_{n}\right)}\right)} \operatorname{deg}(z) \operatorname{deg}(x)$

$$
\begin{aligned}
& =\sum_{\substack{u_{i} u_{s} \\
i \neq s}} \operatorname{deg}\left(u_{i}\right) \operatorname{deg}\left(u_{s}\right)+\sum_{\substack{u_{i} v_{S} \\
i \neq s}} \operatorname{deg}\left(u_{i}\right) \operatorname{deg}\left(v_{s}\right) \\
& +\sum_{u_{i} w_{j}} \operatorname{deg}\left(u_{i}\right) \operatorname{deg}\left(w_{j}\right) \\
& +\sum_{v_{i} v_{S}} \operatorname{deg}\left(v_{i}\right) \operatorname{deg}\left(v_{s}\right) \\
& +\sum_{v_{i} w_{j}}^{i \neq s} \operatorname{deg}\left(v_{i}\right) \operatorname{deg}\left(w_{j}\right) \\
& +\sum_{\substack{w_{j} w_{t} \\
j \neq t}} \operatorname{deg}\left(w_{j}\right) \operatorname{deg}\left(w_{t}\right)
\end{aligned}
$$

$=\frac{|Y|}{2}\left(\frac{|Y|}{2}-1\right)(n !-2)^{2}+\frac{|Y|}{2}\left(\frac{|Y|}{2}-1\right)(n !-2)^{2}+$ $\frac{|Y|}{2}|X|(n !-2)(n !-1)+\frac{|Y|}{2}\left(\frac{|Y|}{2}-1\right)(n !-2)^{2}+$ $\frac{|Y|}{2}|X|(n !-2)(n !-1)+|X|(|X|-1)(n !-1)^{2}$

$=\frac{3|Y|}{2}\left(\frac{|Y|}{2}-1\right)(n !-2)^{2}+|Y||X|(n !-2)(n !-1)+$ $|X|(|X|-1)(n !-1)^{2}$.

c. $\overline{M_{1}}\left(\overline{\Gamma_{\{(1)\}}\left(S_{n}\right)}\right)=\sum_{u_{i} v_{i}}\left[\operatorname{deg}\left(u_{i}\right)+\operatorname{deg}\left(v_{i}\right)\right]$

$=\frac{|Y|}{2}[(n !-2)+(n !-2)]$

$=|Y|(n !-2)$

d. $\quad \overline{M_{2}}\left(\overline{\Gamma_{\{(1)\}}\left(S_{n}\right)}\right)=\sum_{u_{i} v_{i}}\left[\operatorname{deg}\left(u_{i}\right) \operatorname{deg}\left(v_{i}\right)\right]$ $=\frac{|Y|}{2}(n !-2)^{2}$

e. $R M_{2}\left(\overline{\Gamma_{\{(1)\}}\left(S_{n}\right)}\right)=\sum_{u_{i} v_{i}}\left[\operatorname{deg}\left(u_{i}\right)-1\right]\left[\operatorname{deg}\left(v_{i}\right)-\right.$ 1]

$=\frac{|Y|}{2}(n !-3)^{2}$

f. $\quad \Pi_{1}\left(\overline{\Gamma_{\{(1)\}}\left(S_{n}\right)}\right)=\prod_{z \in V\left(\overline{\Gamma_{\{(1)\}}\left(S_{n}\right)}\right)}(\operatorname{deg}(z))^{2}$ 


$$
\begin{aligned}
& =\prod_{z \in Y}(\operatorname{deg}(z))^{2}+\prod_{z \in X}(\operatorname{deg}(z))^{2} \\
& =(n !-2)^{2|Y|}+(n !-1)^{2|X|}
\end{aligned}
$$

g. $\quad \Pi_{2}\left(\overline{\Gamma_{\{(1)\}}\left(S_{n}\right)}\right)=$

$\prod_{z x \in E\left(\overline{\left.\Gamma_{\{(1)\}}\left(S_{n}\right)\right)}\right.}(\operatorname{deg}(z))^{2}(\operatorname{deg}(x))^{2}$

$$
\begin{aligned}
=\prod_{\substack{u_{i} u_{s} \\
i \neq s}} \operatorname{deg}\left(u_{i}\right) \operatorname{deg}\left(u_{s}\right)+\prod_{\substack{u_{i} v_{s} \\
i \neq s}} \operatorname{deg}\left(u_{i}\right) \operatorname{deg}\left(v_{s}\right) \\
+\prod_{u_{i} w_{j}} \operatorname{deg}\left(u_{i}\right) \operatorname{deg}\left(w_{j}\right) \\
+\prod_{\substack{v_{i} v_{s} \\
i \neq s}} \operatorname{deg}\left(v_{i}\right) \operatorname{deg}\left(v_{s}\right) \\
+\prod_{v_{i} w_{j}}^{i \neq g} \operatorname{deg}\left(v_{i}\right) \operatorname{deg}\left(w_{j}\right)
\end{aligned}
$$$$
+\prod_{\substack{w_{j} w_{t} \\ j \neq s}} \operatorname{deg}\left(w_{j}\right) \operatorname{deg}\left(w_{t}\right)
$$$$
=(n !-2)^{3|Y|\left(\frac{|Y|}{2}-1\right)}+[(n !-2)(n !-1)]^{|Y||X|}
$$$$
+(n !-1)^{2|X|(|X|-1)}
$$

h. $\quad E_{1}\left(\overline{\Gamma_{\{(1)\}}\left(S_{n}\right)}\right)=\sum_{z \in V\left(\overline{\Gamma_{\{(1)\}}\left(S_{n}\right)}\right)}(e(z))^{2}$

$$
\begin{aligned}
& =\sum_{z \in Y}(e(z))^{2}+\sum_{z \in X}(e(z))^{2} \\
& =2|Y|+|X| \\
& =n !+|Y|
\end{aligned}
$$

i. $\quad E_{2}\left(\overline{\Gamma_{\{(1)\}}\left(S_{n}\right)}\right)=\sum_{z x \in E\left(\overline{\Gamma_{\{(1)\}}\left(S_{n}\right)}\right)} e(z) e(x)$

$$
\begin{aligned}
=\sum_{\substack{u_{i} u_{s} \\
i \neq s}} e\left(u_{i}\right) e\left(u_{s}\right) & +\sum_{\substack{u_{i} v_{s} \\
i \neq s}} e\left(u_{i}\right) e\left(v_{s}\right) \\
& +\sum_{\substack{u_{i} w_{j} \\
j}} e\left(u_{i}\right) e\left(w_{j}\right) \\
& +\sum_{v_{i} v_{s}}^{\substack{i \neq s \\
i \neq s}} e\left(v_{i}\right) e\left(v_{s}\right)+\sum_{v_{i} w_{j}} e\left(v_{i}\right) e\left(w_{j}\right) \\
& +\sum_{\substack{w_{j} w_{t} \\
j \neq t}} e\left(w_{j}\right) e\left(w_{t}\right)
\end{aligned}
$$$$
=\frac{|Y|}{2}\left(\frac{|Y|}{2}-1\right) 4+\frac{|Y|}{2}\left(\frac{|Y|}{2}-1\right) 4+\frac{|Y|}{2}|X| 2
$$$$
+\frac{|Y|}{2}\left(\frac{|Y|}{2}-1\right) 4+\frac{|Y|}{2}|X| 2
$$$$
+|X|(|X|-1)
$$$$
=6|Y|\left(\frac{|Y|}{2}-1\right)+2|Y||X|+|X|(|X|-1)
$$

$$
\begin{aligned}
& =3|Y|^{2}+|X|^{2}+2|Y||X|-6|Y|-|X| \\
\text { j. } \quad & \xi^{c}\left(\overline{\Gamma_{\{(1)\}}\left(S_{n}\right)}\right)=\sum_{z \in V\left(\overline{\Gamma_{\{(1)\}}\left(S_{n}\right)}\right)} e(z) \operatorname{deg}(z) \\
= & \sum_{z \in Y} e(z) \operatorname{deg}(z)+\sum_{z \in X} e(z) \operatorname{deg}(z) \\
= & |Y| 2(n !-2)+|X| 1(n !-1) \\
= & 2|Y|(n !-2)+|X|(n !-1) \\
\mathrm{k} . \quad & C^{\xi}\left(\overline{\Gamma_{\{(1)\}}\left(S_{n}\right)}\right)=\sum_{z \in V\left(\overline{\Gamma_{\{(1)\}}\left(S_{n}\right)}\right)} \frac{\operatorname{deg}(z)}{e(z)} \\
= & \sum_{z \in Y} \frac{\operatorname{deg}(z)}{e(z)}+\sum_{z \in X} \frac{\operatorname{deg}(z)}{e(z)} \\
= & |Y| \frac{(n !-2)}{2}+|X|(n !-1) \\
& \xi^{d}\left(\overline{\Gamma_{\{(1)\}}\left(S_{n}\right)}\right)=\sum_{z \in V\left(\overline{\Gamma_{\{(1)\}}\left(S_{n}\right)}\right)} e(z) D(z) \\
= & \sum_{z \in Y} e(z) D(z)+\sum_{z \in X} e(z) D(z) \\
= & 2|Y| n !+|X|(n !-1)
\end{aligned}
$$

m. $\quad \xi^{s v}\left(\overline{\Gamma_{\{(1)\}}\left(S_{n}\right)}\right)=\sum_{z \in V\left(\overline{\Gamma_{\{(1)\}}\left(S_{n}\right)}\right)} \frac{e(z) D(z)}{\operatorname{deg}(z)}$

$$
\begin{aligned}
& =\sum_{z \in Y} \frac{e(z) D(z)}{\operatorname{deg}(z)}+\sum_{z \in X} \frac{e(z) D(z)}{\operatorname{deg}(z)} \\
& =\frac{2|Y| n !}{n !-2}+\frac{|X|(n !-1)}{n !-1} \\
& =\frac{2|Y| n !}{n !-2}+|X| .
\end{aligned}
$$

\section{Conclusions}

This article has presented the formulae of some degree-based and eccentric-based topological indices of the subgroup graphs of the symmetric group. The discussion in this article limited on trivial normal subgroups of symmetric group. For further research, examining on non-trivial normal subgroup needed to be studied.

\section{Acknowledgements}

Thank a lot to colleagues and reviewers for their valuable and constructive suggestions to improve the quality of this article.

\section{REFERENCES}

[1] M. R. Darafsheh, "Computation of topological indices of some graphs,” Acta Appl. Math., vol. 110, no. 3, pp. 12251235, 2010. 
[2] A. Ilic, G. Yu, and L. Feng, "On the eccentric distance sum of graphs,” J. Math. Anal. Appl., vol. 381, pp. 590-600, 2011.

[3] M. Azari and A. Iranmanesh, "Computing the eccentric-distance sum for graph operations,” Discret. Appl. Math., vol. 161, no. 18, pp. 2827-2840, 2013.

[4] P. Padmapriya and V. Mathad, "The eccentric-distance sum of some graphs,” Electron. J. Graph Theory Appl., vol. 5, no. 1, pp. 51-62, 2017.

[5] H. Qu and S. Cao, "On the adjacent eccentric distance sum index of graphs,” PLoS One, pp. 1-12, 2015.

[6] I. Gutman, "Degree-based topological indices," Croat. Chem. Acta, vol. 86, no. 4, pp. 351-361, 2014.

[7] R. Khalid and N. Idrees, "Degree-based topological indices of Hanoi graph,” arXiv Prepr. arXiv1804.09431. 2018 Apr 25, 2018.

[8] I. Gutman, B. Furtula, and V. Katanić, "Randić index and information,” AKCE Int. J. Graphs Comb., vol. 15, no. 3, pp. 307-312, 2018.

[9] I. Gutman, E. Milovanović, and I. Milovanović, "Beyond the Zagreb indices,” AKCE Int. J. Graphs Comb., 2018.

[10] R. Rasi, S. M. Sheikholeslami, and A. Behmaram, "An upper bound on the first Zagreb index in trees," Iran. J. Math. Chemstry, vol. 8, no. 1, pp. 71-82, 2017.

[11] T. Došlić, "Vertex-weighted Wiener polynomials for composite graphs,” Ars Math. Contemp., vol. 1, no. 1, pp. 66-80, 2008.

[12] B. Furtula, I. Gutman, and S. Ediz, "On difference of Zagreb indices,” Discret. Appl. Math., vol. 178, pp. 83-88, 2014.

[13] I. Gutman, "Multiplicative zagreb indices of trees," Bull. Soc. Math. Banja Luka, vol. 18, pp. 17-23, 2011.

[14] I. Gutman, B. Furtula, and C. Elphick, "Three new/old vertex-degree-based topological indices,” MATCH Commun. Math. Comput. Chem., vol. 72, pp. 617-632, 2014.

[15] M. Eliasi, A. Iranmanesh, and I. Gutman, "Multiplicative versions of first Zagreb index.," MATCH Commun. Math. Comput. Chem., vol. 68, no. 1, pp. 217-230, 2012.

[16] R. Xing, B. Zhou, and N. Trinajstić, “On Zagreb eccentricity indices,” Croat. Chem. Acta, vol. 84, no. 4, pp. 493-497, 2011.

[17] B. Furtula, I. Gutman, Z. K. Vukicevic, G. Lekishvili, and G. Popivoda, "On an old/new degree-based topological index," Sci. Math., no. 40, pp. 19-31, 2015.

[18] N. De and S. M. A. Nayeem, "Computing the F-index of nanostar dendrimers," Pacific Sci. Rev. A Nat. Sci. Eng., vol. 18, no. 1, pp. 14-21, 2016.

[19] S. Akhter, M. Imran, and M. R. Farahani, "Extremal unicyclic and bicyclic graphs with respect to the F-index," AKCE Int. J. Graphs Comb., vol. 14, no. 1, pp. 80-91, 2017.

[20] R. Kazemi and A. Behtoei, "The first Zagreb and forgotten topological indices of d-ary trees,” Hacettepe J. Math. Stat., vol. 46, no. 4, pp. 603-612, 2017.
[21] B. Furtula and I. Gutman, “A forgotten topological index,” J. Math. Chem., vol. 53, no. 4, pp. 1184-1190, 2015.

[22] L. Zhong, “The harmonic index for graphs,” Appl. Math. Lett., vol. 25, no. 3, pp. 561-566, 2012.

[23] L. Zhong and K. Xu, "The harmonic index for bicyclic graphs,” Util. Math., vol. 90, 2013.

[24] J. Liu, “On the harmonic index of triangle-free graphs,” Appl. Math., vol. 04, no. 08, pp. 1204-1206, 2013.

[25] J. Li and W. C. Shiu, "The harmonic index of a graph," Rocky Mt. J. Math., vol. 44, no. 5, pp. 1607-1620, 2014.

[26] K. C. Das, I. Gutman, and B. Furtula, "On the first geometric-arithmetic index of graphs,” Discret. Appl. Math., vol. 159, no. 17, pp. 2030-2037, 2011.

[27] W. Gao and W. F. Wang, "The fifth geometric-arithmetic index of bridge graph and carbon nanocones,” J. Differ. Equations Appl., vol. 23, no. 1-2, pp. 100-109, 2017.

[28] B. Zhou and N. Trinajstić, "On a novel connectivity index," J. Math. Chem., vol. 46, no. 4, pp. 1252-1270, 2009.

[29] B. Lučić, N. Trinajstić, and B. Zhou, "Comparison between the sum-connectivity index and product-connectivity index for benzenoid hydrocarbons,” Chem. Phys. Lett., vol. 475, no. 1-3, pp. 146-148, 2009.

[30] B. Zhou and N. Trinajstić, "On general sum-connectivity index,” J. Math. Chem., vol. 47, no. 1, pp. 210-218, 2010.

[31] M. R. Farahani, "Some connectivity indices and zagreb index of polyhex nanotubes," Acta Chim. Slov., vol. 59, no. 4, pp. 779-783, 2012.

[32] M. Eliasi, G. Raeisi, and B. Taeri, "Wiener index of some graph operations,” Discret. Appl. Math., vol. 160, no. 9, pp. 1333-1344, 2012.

[33] H. Yousefi-Azari, M. H. Khalifeh, and A. R. Ashrafi, "Calculating the edge Wiener and edge Szeged indices of graphs,” J. Comput. Appl. Math., vol. 235, no. 16, pp. 4866-4870, 2011.

[34] K. C. Das, B. Zhou, and N. Trinajstić, "Bounds on Harary index,” J. Math. Chem., vol. 46, no. 4, pp. 1377-1393, 2009.

[35] B. Zhou, X. Cai, and N. Trinajstić, "On Harary index,” J. Math. Chem., vol. 44, no. 2, pp. 611-618, 2008.

[36] K. Xu and K. C. Das, “On Harary index of graphs,” Discret. Appl. Math., vol. 159, no. 15, pp. 1631-1640, 2011.

[37] Z. Cui and B. Liu, "On Harary matrix, Harary index and Harary energy.,” MATCH Commun. Math. Comput. Chem., vol. 68, no. 3, pp. 815-823, 2012.

[38] K. C. Das, K. Xu, and I. Gutman, “On Zagreb and Harary indices,” Match, vol. 70, no. 1, pp. 301-314, 2013.

[39] N. De, A. Pal, and S. M. A. Nayeem, "Total eccentricity index of some composite graphs,” Malaya J. Mat, vol. 3, no. 4, pp. 523-529, 2015.

[40] N. De, S. M. Abu Nayeem, and A. Pal, "Total eccentricity index of the generalized hierarchical product of graphs," Int. J. Appl. Comput. Math., vol. 1, no. 3, pp. 503-511, 2015. 
[41] N. Idrees, M. J. Saif, A. Rauf, and S. Mustafa, "First and second Zagreb eccentricity indices of thorny graphs," Symmetry (Basel)., vol. 9, no. 7, pp. 1-9, 2017.

[42] H. Hua, "Wiener and Schultz molecular topological indices of graphs with specified cut edges," MATCH Commun. Math. Comput. Chem., vol. 61, no. 3, p. 643, 2009.

[43] V. Andova, D. Dimitrov, J. Fink, and R. Škrekovski, "Bounds on Gutman index,” Match-Communications Math. Comput. Chem., vol. 67, no. 2, p. 515, 2012.

[44] S. Mukwembi, "On the upper bound of Gutman index of graphs," Match-Communications Math. Comput. Chem., vol. 68, no. 1, p. 343, 2012.

[45] M. Knor, P. Potočnik, and R. Škrekovski, "Relationship between the edge-Wiener index and the Gutman index of a graph,” Discret. Appl. Math., vol. 167, pp. 197-201, 2014.

[46] Y. Alizadeh, A. Iranmanesh, and T. Došlić, "Additively weighted Harary index of some composite graphs," Discrete Math., vol. 313, no. 1, pp. 26-34, 2013.

[47] H. Deng, B. Krishnakumari, Y. B. Venkatakrishnan, and S. Balachandran, "Multiplicatively weighted Harary index of graphs,” J. Comb. Optim., 2015.

[48] M. An and L. Xiong, "Multiplicatively weighted harary index of some composite graphs,” Filomat, 2015.

[49] M. K. Jamil, "Distance-based topological indices and double graph,” Iran. J. Math. Chem., vol. 8, no. 1, pp. 83-91, 2017.

[50] T. Došlić, M. Saheli, and D. Vukičević, "Eccentric connectivity index: extremal graphs and values,” Iran. J. Math. Chem., vol. 1, no. 2, pp. 45-56, 2010.

[51] A. Ilic and I. Gutman, "Eccentric connectivity index of chemical trees,” MATCH Commun. Math. Comput. Chem., vol. 65, pp. 731-744, 2011.

[52] T. Došlic and M. Saheli, "Eccentric connectivity index of composite graphs,” Util. Math, no. February, pp. 1-20, 2015.

[53] R. S. Haoer, K. A. Atan, A. M. Khalaf, M. R. M. Said, and R. Hasni, "Eccentric connectivity index of chemical trees," in AIP Conference Proceedings, 2016, vol. 1739, no. 1, p. 20043.

[54] G. Yu and L. Feng, "On connective eccentricity index of graphs.,” MATCH Commun. Math. Comput. Chem., vol. 69, no. 3, pp. 611-628, 2013.

[55] K. Balasubramanian, S. Balachandran, S. R. Balachandar, and S. G. Venkatesh, "Computing eccentric distance sum of dendrimers and nanotubes,” Int. J. Pharm. Technol., vol. 9, no. 1, pp. 28728-28738, 2017.

[56] M. Songhori, “A note on eccentric distance sum,” J. Math. Nanosci., vol. 2, no. 1, pp. 37-41, 2012.

[57] B. Eskender, E. Vumar, and A. R. Ashrafi, "Eccentric connectivity index and eccentric distance sum of some graph operations,” Trans. Comb. ISSN, vol. 2, no. 1, pp. 2251-8657, 2013.

[58] H. Bielak and K. Broniszewska, "Eccentric distance sum index for some classes of connected graphs,” Ann. Univ. Mariae Curie-Sklodowska, Sect. A - Math., vol. 71, no. 2, p.
25, 2019.

[59] S. Gupta, M. Singh, and A. K. Madan, "Eccentric distance sum : A novel graph invariant for predicting biological and physical properties,” J. Math. Anal. Appl., vol. 275, pp. 386-401, 2002.

[60] F. Dayan, B. Ahmad, M. Zulqarnain, U. Ali, Y. Ahmad, and T. J. Zia, "On some topological indices of triangular silicate and triangular oxide networks,” Int. J. Pharm. Sci. Res., vol. 9, no. 10, pp. 4326-4331, 2018.

[61] W. Gao, W. Wang, and M. R. Farahani, "Topological indices study of molecular structure in anticancer drugs,” J. Chem., vol. 2016, 2016.

[62] W. Gao, M. R. Rajesh Kanna, E. Suresh, and M. R. Farahani, "Calculating of degree-based topological indices of nanostructures,” Geol. Ecol. Landscapes, vol. 1, no. 3, pp. 173-183, 2017.

[63] S. Gupta, M. Singh, and A. K. Madan, "Connective eccentricity index: a novel topological descriptor for predicting biological activity,” J. Mol. Graph. Model., vol. 18, no. 1, pp. 18-25, 2000.

[64] R. Malpashree, "Some degree and distance based topological indices of vertex-edge corona of two graphs.," J. Int. Math. Virtual Inst., vol. 6, pp. 1-29, 2016.

[65] L. Miao, Q. Cao, N. Cui, and S. Pang, "On the extremal values of the eccentric distance sum of trees,” Discret. Appl. Math., vol. 186, no. 1, pp. 199-206, 2015.

[66] Y. Nacaroglu and A. D. Maden, "On the eccentric connectivity index of unicyclic graphs,” Iran. J. Math. Chem., vol. 9, no. 1, pp. 47-56, 2018.

[67] K. Pattabiraman and P. Paulraja, "On some topological indices of the tensor products of graphs,” Discret. Appl. Math., vol. 160, no. 3, pp. 267-279, 2012.

[68] M. R. Rajesh Kanna, Pradeep Kuamr R, and Soner Nandappa D, "Computation of topological indices of windmill graph,” Int. J. Pure Appl. Math., vol. 119, no. 1, pp. 89-98, 2018.

[69] J. A. Rodriguez, "On the Wiener index and the eccentric distance sum of hypergraphs," MATCH Commun. Math. Comput. Chem., vol. 54, pp. 209-220, 2005.

[70] M. K. Siddiqui, M. Naeem, N. A. Rahman, and M. Imran, "Computing topological indices of certain networks," J. Optoelectron. Adv. Mater., vol. 18, no. 9-10, pp. 884-892, 2016.

[71] G. Yu, L. Feng, and A. Ilic, "On the eccentric distance sum of trees and unicyclic graphs,” J. Math. Anal. Appl., vol. 375, pp. 99-107, 2011.

[72] X. Zhang, "Some degree-based topological indices of base-3 sierpiński graphs,” Sci. J. Chem., vol. 5, no. 3, p. 36, 2017.

[73] N. I. Alimon, N. H. Sarmin, and A. Erfanian, "Topological indices of non-commuting graph of dihedral groups," Malaysian J. Fundam. Appl. Sci., vol. 14, pp. 473-476, 2018.

[74] D. F. Anderson, J. Fasteen, and J. D. Lagrange, "The subgroup graph of a group,” Arab J. Math., vol. 1, pp. 1727, 2012. 
[75] F. Kakeri and A. Erfanian, “The complement of subgroup graph of a group,” J. Prime Res. Math., vol. 11, pp. 55-60, 2015.

[76] S.-F. Du, Y.-Q. Feng, J. H. Kwak, and M.-Y. Xu, "Cubic Cayley graphs on dihedral groups,” Math. Anal. Appl., vol. 7, pp. 224-234, 2004.

[77] C. Wang and M. Xu, "Non-normal one-regular and 4-valent Cayley graphs of dihedral groups D2n,” Eur. J. Comb., vol. 27, no. 5, pp. 750-766, 2006.

[78] T. T. Chelvama, K. Selvakumar, and S. Raja, "Commuting graphs on dihedral group,” TJMCS, vol. 2, pp. 402-406, 2011.

[79] Abdussakir, D. A. Akhadiyah, A. Layali, and A. T. Putra, "Q-spectral and L-spectral radius of subgroup graphs of dihedral group,” J. Phys. Conf. Ser., vol. 1114, no. 012110, pp. 1-6, 2018.

[80] Abdussakir, E. Susanti, Turmudi, M. N. Jauhari, and N. M. Ulya, "On the distance spectrum and distance energy of complement of subgroup graphs of dihedral group,” J. Phys. Conf. Ser., 2018.
[81] Abdussakir, D. A. Akhadiyah, A. Layali, and A. T. Putra, "The adjacency spectrum of subgroup graphs of dihedral group,” IOP Conf. Ser. Earth Environ. Sci., vol. 243, no. 1, 2019.

[82] Abdussakir, D. C. A. Putri, and Z. R. Fadhillah, "Full automorphism group of commuting and non-commuting graph of dihedral and symmetric groups," in Journal of Physics: Conference Series, 2018, pp. 1-5.

[83] A. Nawawi and P. Rowley, "On commuting graphs for elements of order 3 in symmetric groups,” Electron. J. Comb., vol. 22, no. 1, pp. 1-12, 2015.

[84] T. Woodcock, "The commuting graph of the symmetric group Sn,” Int. J. Contemp. Math. Sci., vol. 10, no. 6, pp. 287-309, 2015.

[85] G. Chartrand, L. Lesniak, and P. Zhang, Graphs \& digraphs, Sixth Edit. Boca Raton: CRC Press, 2016.

[86] V. Sharma, R. Goswami, and A. K. Madan, "Eccentric connectivity index: a novel highly discriminating topological descriptor for structure- property and structure- activity studies," J. Chem. Inf. Comput. Sci., vol. 37, no. 2, pp. 273-282, 1997. 